\title{
Gratitude at the end of life: a promising lead for palliative care
}

2

3

4

5

6

8

11 Design - We performed an exploratory and cross-sectional study with palliative patients of the

12 Lausanne University Hospital.

13 Measurements - We used the Gratitude Questionnaire, the McGill-Quality of Life

14 questionnaire, the Hospital Anxiety and Depression Scale, the Post-traumatic Growth Inventory,

15 and the health status items of the Eastern Cooperative Oncology Group. Spearman correlations 16 and multivariate analyses were performed.

17 Results - Sixty-four patients participated (34 women, mean age=67). The results showed 18 significant positive correlations between gratitude and quality of life ( $r=.376)$, and the appreciation 19 of life dimension of the post-traumatic growth $(r=.426)$. Significant negative correlations were 20 found between gratitude and psychological distress $(r=-.324)$, and health status $(r=-.266)$. The 21 best model for QOL explained $47.6 \%$ of the variance $(F=26.906)$ and included psychological 


\section{Gratitude in palliative care}

22 distress and gratitude. The relational dimension was the most frequently cited source of gratitude $23(61 \%)$.

24 Conclusion - Gratitude may act positively on QOL and may protect against psychological 25 distress in the palliative situation. The next step will be the adaptation and implementation of a 26 gratitude-based intervention.

27 Keywords - gratitude, palliative care, quality of life, psychological distress, positive psychology 28 


\section{Gratitude at the end of life: a promising lead for palliative care}

30

31

32

\section{BACKGROUND}

Promoting a holistic approach to care, palliative care aims to improve quality of life by preventing and relieving pain and other physical, psychological and existential problems associated with a life-threatening illness (1). From a psychological perspective, research largely has focused on improving the pharmacological treatments for frequently occurring psychopathologies, such as anxiety or depression (2). Less is known about factors fostering psychological well-being and improving quality of life. Positive psychology represents a theoretical paradigm that is complementary to clinical psychopathology and concentrates on positive subjective experiences, individual traits, and institutions to improve quality of life and prevent pathologies (3). Among its different topics, gratitude seems particularly relevant for palliative care $(4,5)$.

In the psychology literature, gratitude is considered either as an emotional state or as a personality disposition (5-7). As an emotional state, gratitude consists of two main aspects: a positive state that an individual consciously experiences when he receives a benefit; and the recognition that the source of this benefit was someone or something else, such as life or a more spiritual entity (8). When gratitude is experienced more regularly and more intensely than average, we speak about gratitude as a dispositional trait. At this level, gratitude is often perceived as "a life orientation towards noticing and appreciating the positive in the world" (5, p.891). Beyond psychology, it is also worth mentioning that gratitude is perceived as a central dimension in traditional religious worldviews since it represents a way "to relieve guilt from moral failure" (9, 10), and more widely of spirituality since gratitude involves an appraisal of something as meaningful (11). 
51 Recently, relationships between gratitude and important outcomes of palliative care have been

52 examined in the general population. Significant links were reported between gratitude and anxiety

53 (12), depression (11, 13-15), and death anxiety $(16,17)$. Two longitudinal studies highlighted that

54 gratitude was a significant predictor of decreased depression and psychological distress (18).

55 Earliest clinical data have come from oncological populations, where its relevance was validated $56(19-21)$.

57 Psychological traits are by definition more stable than emotions, which tend to be short-lived and 58 transient. Given the lack of data on gratitude in the palliative care context, we have specifically 59 chosen to consider gratitude as a personality trait in this study in order to obtain reliable data.

60 We hypothesized that dispositional gratitude represents a positive psychological factor in the 61 palliative care setting, contributes to the patient's quality of life, psychological wellbeing and 62 performance status. The aims of the study were $(A)$ to explore the relation between gratitude and 63 (i) quality of life, (ii) psychological distress, (iii) post traumatic growth and (iv) health status for 64 patients in a palliative care situation; and $(B)$ to investigate to what extent these variables 65 contribute to the patients' quality of life. An ancillary point of interest was (C) to assess which life 66 domains were identified by the patients as sources of gratitude.

\section{METHODS}

68 This is a cross-sectional study utilizing quantitative methods consisting of validated 69 questionnaires. 
71 The study was conducted at the Lausanne University Hospital in Switzerland. Data collection took

72 place from 2015 to 2017, with questionnaires completed during face-to-face interviews. Patients

73 were recruited from the Palliative and Supportive Care Service and identified by the clinical team

74 based on the eligibility criteria.

75 Inclusion criteria consisted of age $>18$, enrollment in palliative care, a stable physical state for the 76 last 24 hours, and suffering from a progressive disease with reduced life expectancy. Exclusion

77 criteria comprised the presence of cognitive or psychiatric disorder impairing decision-making

78 capacity and the existence of severe communication problems (foreign language, deafness).

79 After identification by the palliative care team, patients were approached by an independent 80 research collaborator who informed them about the study objectives, obtained written consent 81 and administered the questionnaires.

\section{Measures}

\section{Socio-demographic and medical assessments}

84 The attending physician in charge of the patient collected socio-demographic and medical data: 85 age, sex, nationality, mother tongue, marital status, education, profession, primary diagnosis, and 86 co-morbidities.

87 Quality of life was assessed by The McGill-Quality of Life questionnaire revised version (MQLL88 R) (22). The MQoL-R was developed for the setting of end of life. It contains 14 items (range from 890 to 10 , with higher score reflecting higher quality of life) forming an overall total score and four 90 subscales scores: physical, psychological, existential, and social. Item example: "Over the past 
91 two days, I was depressed: 0-not at all to 10-extremely". The tool starts with a single item

92 assessing overall subjective quality of life. MQoL-R was translated into French (22).

93 Gratitude was measured using The Gratitude Questionnaire 6 items (GQ-6) (23). The GQ-6 is a 94 widely used measure of gratitude and contains six items (e.g. "I have so much in life to be thankful 95 for") rated on a Likert scale. The GQ-6 allows a measure of trait gratitude on four co-occurring 96 dimensions: density, span, frequency and intensity. This questionnaire was validated in French 97 (24). Following this questionnaire, we asked participants to name those life domains that represented sources of gratitude for them.

99 Psychological distress was examined using the Hospital Anxiety and Depression Scale (HADS) 100 (25). The HADS consists of 14 items (e.g. "I feel as if I am slowed down") rated on a Likert scale 101 yielding a total score (0-42), a depression score (0-21) and an anxiety score (0-21), with higher 102 scores reflecting higher distress. The scale was validated in French (26).

103 Post-traumatic growth was assessed with the Post-traumatic Growth Inventory (PTGI) (27). This 104 questionnaire includes 21 items based on a Likert scale, each describing a potential change 105 arisen because of a stressful event (e.g. "I can better appreciate each day"). The questionnaire 106 includes a total score (0-105) and five subscales: better relation with others (0-35), new 107 possibilities (0-25), personal strengths (0-20), spiritual changes (0-10), and appreciation of life (0108 15). We used a translated French version (28).

109 To assess potential negative aspects of the disease experience and mitigate positivity bias, we 110 included two complementary items (NRS 0-10) that were administered prior to the PTGI: 111 "Globally, to what extent would you say that your disease has negatively (Q1) / positively (Q2) 112 changed you as a person and/or your life?". 
113 Health status was assessed using the Eastern Cooperative Oncology Group (ECOG) (29). The

114 ECOG is a measurement of a patient's levels of functioning and autonomy in terms of their daily 115 activities, and living and physical abilities. It consists in five grades going from "0 - Fully active, 116 able to carry on all pre-disease performance without restriction" to " 5 - Death". The ECOG 117 performance status was filled out with the physician or nurse in charge of the patient.

\section{Statistical analyses}

119 Descriptive statistical analyses were performed on the demographic variables and the 120 questionnaire data. To address our first aim, we used bivariate Spearman correlations on 121 gratitude in relation with quality of life, post-traumatic growth, psychological distress and health 122 status. Spearman correlations were chosen instead of Pearson correlations given the non-normal 123 distributions of some variables and the existence of some outlier values.

124 To address our second aim, multiple linear regression analyses (enter method) were performed 125 with Quality of life (MQoL total score) as dependent variable and health status (ECOG), 126 psychological distress (HADS total score), post-traumatic growth (PTGI total score) and gratitude 127 (GQ-6 total score) as independent variables. To obtain a more parsimonious model, we performed 128 a second linear regression, using the stepwise methods, including only the significant predictors 129 from the first model. Since, according to the literature, at least 10 to 15 observations are needed 130 for each predictor $(30,31)$, we only used the total score of each questionnaire in the analyses.

131 To address our final aim, the research collaborator used an open-ended approach to ask each 132 patient which life domain(s) he/she identified as a source of gratitude. We analyzed the responses 133 based on pre-existing categories adapted for this study from the Schedule for Meaning in Life 134 Evaluation (32). The proportion of agreement between two independent evaluators (BA and MB) 135 was calculated on $30 \%$ of the total domains. 
136 Regarding missing data, MQoL and PTGI scores were calculated using mean imputation if no

137 more than one item score were missing for a given subscale (22). Concerning the HADS,

138 participants' subscale mean were calculated if at least half of the items were answered (33). Three

139 participants did not complete the GQ-6 questionnaire and were excluded from the analyses.

140 In accordance with the exploratory approach of our study, we set a significance level at $p=0.05$

141 without Bonferroni correction.

143 This study was funded by the Leenaards Foundation and approved by the ethics committee of

144 the Lausanne University Hospital.

145 RESULTS

147 A total of 164 patients were identified as eligible by the clinical team. Out of these, 64 patients 148 agreed to participate in the study (39\% acceptance rate). Reasons for refusal were "doesn't want 149 to participate" (16\%), "no longer a patient of the palliative care service" (13\%), "psychological" 150 (10\%) or "physical" (9\%) problems, "exclusion criteria present" (7\%), "deceased" (4\%) or "lost to 151 follow-up" (2\%). Socio-demographic data are shown in table 1.

152 [Insert table 1 here]

\section{Descriptive analyses}

154 Table 2 shows the descriptive statistics for each questionnaire used.

155 [Insert table 2 here] 
157 To the questions: "Globally, to what extent would you say that your disease changed negatively

158 or positively your person and/or your life?", patients answered with a mean of $5.48(S D=3.4)$ for 159 the negative changes and a mean of $4.33(S D=3.5)$ for the positive changes following the illness. traumatic growth and health status (aim A)

162 The results of the Spearman correlation analyses are shown in Table 3. Notably, the data showed 163 a significant positive association between gratitude (GQ6 total score) and global quality of life 164 (MQoL total score), as well as with three MQoL subscales (physical, psychological, and 165 existential). The data also indicated a significant negative association between gratitude and 166 global psychological distress (HADS total score) and health status (ECOG score).

167 [Insert table 3 here]

169 The results of the linear regression model showed that $51.9 \%$ of the variance of overall quality of 170 life (MQoL total score) was explained by gratitude, psychological distress, post-traumatic growth 171 and health status, with gratitude and psychological distress as significant predictors (adjusted $\mathrm{R}^{2}=$ 172 519; $F=15.588 ; p=.000$; see table 4).

\section{3 [Insert table 4 here]}

174 We performed a second linear regression (stepwise method) using only psychological distress 175 and gratitude. The results (table 5) showed that these variables explained almost $48 \%$ of the 
176 variance of quality of life (adjusted $\mathrm{R} 2=.476 ; \mathrm{F}=26.906 ; \mathrm{p}=.000$; psychological distress $43.8 \%$,

177 gratitude $3.8 \%)$.

178 [Insert table 5 here]

180 An average of 3.78 sources of gratitude per participant were mentioned. They were classified in

18111 dimensions (see figure 1), with "family and friends", representing the most cited dimension

$182(57 \%)$. Concerning the classification of the cited domains, 89.5\% agreement was found between

183 the two independent evaluators.

184 [Insert figure 1 here]

185 DISCUSSION

186 To our knowledge, this is the first study to examine the relevance of dispositional gratitude in the 187 palliative care context. In this setting, we found a weak to moderate positive correlation between 188 gratitude and overall quality of life as well as its physical, physiological and existential subscales. 189 These results are supported by previous research in other clinical settings (34-36). Notably, the 190 strongest relationship was found with the existential dimension of QOL. This lends support to the 191 hypothesis that gratitude may improve meaning in life and could reinforce spirituality $(7,37)$.

192 Gratitude did not correlate significantly with the relational dimension of quality of life. This point 193 was surprising given the fact that patients mentioned social relationships (and particularly family 194 and friends) as a major source of gratitude for them. This could be explained, in part, by the fact 195 that the GQ-6 does not measure gratitude according to the quality of the relationship but more in 196 terms of the quantity of people towards whom gratitude is experienced (the "density" facet of the 
GQ-6). In addition, the GQ-6 measures gratitude with four dimensions and provides a total final score, which is unidimensional; thus, the relational aspect of gratitude could not be investigated independently of the total score even though it may have been important. We also found a weak to moderate negative relationship of gratitude with psychological distress and with depressive symptoms, consistent with previous findings in clinical settings $(13,20,38)$.

202 It is also worth mentioning that one of the strongest associations found concerns gratitude and 203 life appreciation, one of the PTGI's subscales. Several authors emphasize that appreciation (of 204 life but also for simple pleasures and others) represents an essential component of gratitude (5, 205 6). This aspect may support the hypothesis that gratitude, through the appreciation experience, can be a specific factor in the post-traumatic growth process that may help people to adapt to a traumatic event such as a life-threatening illness $(5,39,40)$.

208 A closer look at the items of PTGI may explain in part why we did not observe significant 209 correlations with the other PTGI subscales. The "new possibility" dimension includes items describing having new opportunities or interests, which does not match with the definition of

211 gratitude as an appreciation of what someone already has. The items of the "personal strengths" 212 subscale describe an ability to cope with the disease, an aspect that is not included in the GQ-6 213 questionnaire. Finally, the "spiritual changes" dimension was very close to the significance level $214(p=.055)$, which may be due to our relatively small sample.

215 Regarding our second aim, the most parsimonious model shows a strong impact of psychological 216 distress on quality of life, explaining almost $44 \%$ of the variance. As the only other significant 217 factor in this model, gratitude explained another 4\% of QOL variance. These results confirm that 218 psychological distress represents a major issue for palliative care (41-43). They also point out 219 that positive dimensions such as gratitude play a significant role and could represent useful 
220 resources for improving the quality of life of palliative care patients. This finding is consistent with

221 the patients' responses to the two additional items administered prior to the PTGI where patients

222 reported experiencing positive and negative illness consequences in almost equal proportions.

223 The correlations found in this research between gratitude and quality of life and positive 224 psychological changes on one hand and psychological distress on the other hand raise questions 225 about the processes involved. As a positive trait and emotion, gratitude can be viewed within the 226 broaden-and-build theory of emotions (44). According to this paradigm, gratitude's role is to 227 broaden people's thought-action repertoire. This process would result in an expansion of personal 228 resources that can be noticed at two levels specific for gratitude: an increase in spirituality and a 229 development of interpersonal resources, both of which contribute to global quality of life $(6,21$, 230 45). Concerning the interaction between gratitude and psychological distress, Lambert, Fincham 231 and Stillman (46) showed that people higher in the gratitude trait tend to positively reframe 232 previous negative events by perceiving them as opportunities for growth, facilitating the 233 emergence of positive emotions such as gratitude and the decrease of depressive and anxious 234 symptoms $(5,46)$.

235 Finally, our findings indicate that family and friends are the most cited resource of gratitude for 236 palliative patients. Interpersonal and particularly familial relationships are known to be crucial for 237 palliative care patients, contributing to both their meaning in life (47-49) and their quality of life $238(50,51)$. As an "other-oriented" emotion, gratitude shows a positive impact on relationship-related 239 dimension such as feelings of social affiliation (52), relational commitment (53), satisfaction with 240 relationships $(54,55)$, and partner reciprocal maintenance behaviors $(52,53,56)$.

241 There are several limitations to the present study. First, the cross-sectional design does not allow 242 inferring causality in the associations highlighted between the variables. Second, our relatively 
243 small sample size and sometimes high level of missing data (i.e. for the PTGI) leads to a low

244 statistical power. Third, the use of the GQ-6 for assessing gratitude does not allow a complete 245 understanding of the individual characteristics of gratitude (e.g. the quality of the relationships is 246 not considered). Future research could utilize a different gratitude tool such as the S-GRAT (57)

247 to allow for an in-depth examination of dispositional gratitude. Fourth, in light of the generally high 248 scores on the gratitude scale, a social desirability bias may have influenced our results (58). We 249 strove to minimize this bias using a research investigator not connected to the clinical team. 250 Finally, as most palliative care studies, the participation rate was low, which may contribute to a 251 selection bias favoring patients with higher levels of psychological wellbeing and performance 252 status.

253 In summary, this study supports the hypothesis that gratitude may have a positive impact on 254 quality of life in palliative care patients, and may help reducing psychological distress at end of 255 life. Since the main sources of gratitude are based on social support, which in turn is known to 256 contribute strongly to quality of life and meaning in life of palliative care patients, we are currently 257 in the process of developing a gratitude-based intervention involving patients as well as family 258 caregivers.

\section{AUTHOR DISCLOSURE STATEMENT}

260 No competing financial interests exist.

261 ACKNOWLEDGMENTS

262 We sincerely thank the Leenaards Foundation, as well as Prof André Berchtold from the Institute 263 of Psychology of the University of Lausanne for his precious help with statistical analyses. 


\section{REFERENCES}

265 1. World Health Organisation. Global atlas of palliative care at the end of life 2014. Available 266 from: http://www.who.int/cancer/palliative/definition/en/.

267 2. Parpa E, Tsilika E, Gennimata V, Mystakidou K. Elderly cancer patients' psychopathology:

268 A systematic review: Aging and mental health. Archives of Gerontology and Geriatrics. $269 \quad 2015 ; 60(1): 9-15$.

270 3. Seligman ME, Csikszentmihalyi M. Positive psychology. An introduction. Am Psychol. $271 \quad 2000 ; 55(1): 5-14$

272 4. Bernard M. Le sentiment de gratitude en soins palliatifs : un facteur psychologique 273 contribuant au bien-être et à la qualité de vie ? Psycho-Oncologie. 2015;9(2):115-20.

274 5. Wood AM, Froh JJ, Geraghty AWA. Gratitude and well-being: A review and theoretical 275 integration. Clinical Psychology Review. 2010;30(7):890-905.

276 6. Watkins PC, Bell J. Current theories and research in the psychology of gratitude. Scientific 277 advances in positive psychology. Santa Barbara, CA: Praeger/ABC-CLIO; US; 2017. p. $103-29$.

278 7. Ruini C. Gratitude, Spirituality and Meaning: Their Clinical Implications. In: Ruini C, editor. 279 Positive Psychology in the Clinical Domains: Research and Practice. Cham: Springer 280 International Publishing; 2017. p. 179-203.

281 8. Emmons RA. Thanks!: How Practicing Gratitude Can Make You Happier: Houghton Mifflin 282 Company; 2008.

283 9. R. Lavelock C, Griffin B, Worthington E, G. Benotsch E, Lin Y, Greer C, et al. A Qualitative 284 Review and Integrative Model of Gratitude and Physical Health2016. 55-86 p.

285 10. Bethune GW, Trust BoT. Guilt, Grace and Gratitude: Lectures on the Heidelberg 286 Catechism: Banner of Truth Trust; 2001. 
287 11. Emmons RA, McCullough ME. Counting blessings versus burdens: An experimental 288 investigation of gratitude and subjective well-being in daily life. Journal of Personality and Social 289 Psychology. 2003;84(2):377-89.

290 12. Stoeckel M, Weissbrod C, Ahrens A. The Adolescent Response to Parental IIIness: The 291 Influence of Dispositional Gratitude. Journal of Child and Family Studies. 2015;24(5):1501-9.

292 13. Sirois FM, Wood AM. Gratitude uniquely predicts lower depression in chronic illness 293 populations: A longitudinal study of inflammatory bowel disease and arthritis. Health Psychology. $294 \quad 2017 ; 36(2): 122-32$.

295 14. Seligman ME, Steen TA, Park N, Peterson C. Positive psychology progress: Empirical 296 validation of interventions. Tidsskrift for Norsk Psykologforening. 2005;42(10):874-84 .

297 15. Disabato DJ, Kashdan TB, Short JL, Jarden A. What Predicts Positive Life Events that 298 Influence the Course of Depression? A Longitudinal Examination of Gratitude and Meaning in 299 Life. Cognitive Therapy and Research. 2017;41(3):444-58.

300 16. Lau RWL, Cheng S-T. Gratitude lessens death anxiety. European Journal of Ageing. $301 \quad 2011 ; 8(3): 169$.

302 17. Lau RWL, Cheng S-T. Gratitude Orientation Reduces Death Anxiety but Not Positive and 303 Negative Affect. OMEGA - Journal of Death and Dying. 2013;66(1):79-88.

304 18. Wood AM, Maltby J, Gillett R, Linley PA, Joseph S. The role of gratitude in the 305 development of social support, stress, and depression: Two longitudinal studies. Journal of 306 Research in Personality. 2008;42(4):854-71.

307 19. Otto AK, Szczesny EC, Soriano EC, Laurenceau J-P, Siegel SD. Effects of a randomized 308 gratitude intervention on death-related fear of recurrence in breast cancer survivors. Health 309 Psychology. 2016;35(12):1320-8. 
$31020 . \quad$ Ruini C, Vescovelli F. The role of gratitude in breast cancer: Its relationships with post-

311 traumatic growth, psychological well-being and distress. Journal of Happiness Studies.

$312 \quad 2013 ; 14(1): 263-74$.

313 21. Algoe SB, Stanton AL. Gratitude when it is needed most: social functions of gratitude in 314 women with metastatic breast cancer. Emotion. 2012;12(1):163-8.

315 22. Cohen SR, Sawatzky R, Russell LB, Shahidi J, Heyland DK, Gadermann AM. Measuring 316 the quality of life of people at the end of life: The McGill Quality of Life Questionnaire-Revised. 317 Palliative Medicine. 2017;31(2):120-9.

318 23. McCullough ME, Emmons RA, Tsang J-A. The grateful disposition: A conceptual and 319 empirical topography. Journal of Personality and Social Psychology. 2002;82(1):112-27.

320 24. Shankland R, Vallet F. Le questionnaire d'orientation reconnaissante. Manuscrit non 321 publié à ce jour. Grenoble/Université de Savoie - Chambéry: Université Pierre Mendès; 2011.

322 25. Zigmond AS, Snaith RP. The Hospital Anxiety and Depression Scale. Acta Psychiatrica 323 Scandinavica. 1983;67(6):361-70.

324 26. Razavi D, Delvaux N, Farvacques C, Robaye E. Validation of the French version of the 325 Hospital Anxiety and Depression Scale (HADS) in a population of hospitalized cancer patients. 326 Validation de la version francaise du HADS dans une population de patients cancereux 327 hospitalises. 1989;39(4):295-307.

328 27. Tedeschi RG, Calhoun LG. The Posttraumatic Growth Inventory: Measuring the positive 329 legacy of trauma. Journal of Traumatic Stress. 1996;9(3):455-72.

330 28. Lelorain S, Bonnaud-Antignac A, Florin A. Long Term Posttraumatic Growth After Breast 331 Cancer: Prevalence, Predictors and Relationships with Psychological Health. Journal of Clinical 332 Psychology in Medical Settings. 2010;17(1):14-22. 
333 29. Oken MM, Creech RH, Tormey DC, Horton J, Davis TE, McFadden ET, et al. Toxicity and 334 response criteria of the Eastern Cooperative Oncology Group. American journal of clinical 335 oncology. 1982;5(6):649-55.

336 30. Bressoux P. Modélisation statistique appliquée aux sciences sociales. Louvain-la-Neuve:

337 De Boeck Supérieur; 2010. 464 p.

338 31. Howell DC, Yzerbyt V, Bestgen Y, Rogier M. Méthodes statistiques en sciences humaines: 339 De Boeck Supérieur; 2008.

340 32. Fegg MJ, Kramer M, L'Hoste S, Borasio GD. The Schedule for Meaning in Life Evaluation 341 (SMiLE): validation of a new instrument for meaning-in-life research. J Pain Symptom Manage. $342 \quad 2008 ; 35(4): 356-64$.

343 33. Bell ML, Fairclough DL, Fiero MH, Butow PN. Handling missing items in the Hospital 344 Anxiety and Depression Scale (HADS): a simulation study. BMC Research Notes. 2016;9:479.

345 34. Eaton RJ, Bradley G, Morrissey S. Positive predispositions, quality of life and chronic 346 illness. Psychology, Health \& Medicine. 2014;19(4):473-89.

347 35. Toussaint L, Friedman P. Forgiveness, Gratitude, and Well-Being: The Mediating Role of 348 Affect and Beliefs. Journal of Happiness Studies. 2008;10(6):635.

349 36. Mills PJ, Redwine L, Wilson K, Pung MA, Chinh K, Greenberg BH, et al. The role of 350 gratitude in spiritual well-being in asymptomatic heart failure patients. Spirituality in Clinical 351 Practice. 2015;2(1):5-17.

352 37. Emmons R, A. Crumpler C. Gratitude as a Human Strength: Appraising the Evidence2000. $353 \quad 56-69 \mathrm{p}$.

354 38. Shao D, Gao W, Cao F-L. Brief psychological intervention in patients with cervical cancer: 355 A randomized controlled trial. Health Psychology. 2016;35(12):1383-91. 
356 39. Davis CG, Nolen-Hoeksema S, Larson J. Making sense of loss and benefiting from the 357 experience: two construals of meaning. J Pers Soc Psychol. 1998;75(2):561-74.

358 40. Greene N, McGovern K. Gratitude, psychological well-being, and perceptions of 359 posttraumatic growth in adults who lost a parent in childhood. Death Studies. 2017;41(7):436-46.

360 41. Garrison CM, Overcash J, McMillan SC. Predictors of Quality of Life in Elderly Hospice 361 Patients with Cancer. Journal of hospice and palliative nursing : JHPN : the official journal of the 362 Hospice and Palliative Nurses Association. 2011;13(5):288-97.

363 42. Mitchell AJ, Chan M, Bhatti H, Halton M, Grassi L, Johansen C, et al. Prevalence of 364 depression, anxiety, and adjustment disorder in oncological, haematological, and palliative-care 365 settings: a meta-analysis of 94 interview-based studies. The Lancet Oncology. 2011;12(2):16036674.

367 43. Bernard M, Strasser F, Gamondi C, Braunschweig G, Forster M, Kaspers-Elekes K, et al. 368 Relationship Between Spirituality, Meaning in Life, Psychological Distress, Wish for Hastened 369 Death, and Their Influence on Quality of Life in Palliative Care Patients. Journal of Pain and 370 Symptom Management. 2017;54(4):514-22.

371 44. Fredrickson BL. The broaden-and-build theory of positive emotions. Philosophical 372 Transactions of the Royal Society B: Biological Sciences. 2004;359(1449):1367-78.

373 45. Algoe SB, Fredrickson BL, Gable SL. The social functions of the emotion of gratitude via 374 expression. Emotion. 2013;13(4):605-9.

375 46. Lambert NM, Fincham FD, Stillman TF. Gratitude and depressive symptoms: The role of 376 positive reframing and positive emotion. Cognition and Emotion. 2012;26(4):615-33.

377 47. Tomas-Sabado J, Villavicencio-Chavez C, Monforte-Royo C, Guerrero-Torrelles M, Fegg 378 MJ, Balaguer A. What gives meaning in life to patients with advanced cancer? A comparison 
379 between Spanish, German, and Swiss patients. Journal of Pain and Symptom Management. $380 \quad 2015 ; 50(6): 861-6$.

381 48. Fegg MJ, Kögler M, Brandstätter M, Jox R, Anneser J, Haarmann-Doetkotte S, et al. 382 Meaning in life in patients with amyotrophic lateral sclerosis. Amyotrophic Lateral Sclerosis. $383 \quad 2010 ; 11(5): 469-74$.

384 49. Stiefel F, Krenz S, Zdrojewski C, Stagno D, Fernandez M, Bauer J, et al. Meaning in life 385 assessed with the "Schedule for Meaning in Life Evaluation" (SMiLE): a comparison between a 386 cancer patient and student sample. Supportive Care in Cancer. 2008;16(10):1151-5.

387 50. Giovannetti AM, Pietrolongo E, Giordano A, Cimino V, Campanella A, Morone G, et al. 388 Individualized quality of life of severely affected multiple sclerosis patients: practicability and value 389 in comparison with standard inventories. Quality of Life Research. 2016;25(11):2755-63.

390 51. Neudert C, Wasner M, Borasio GD. Individual Quality of Life is not Correlated with Health391 Related Quality of Life or Physical Function in Patients with Amyotrophic Lateral Sclerosis. 392 Journal of Palliative Medicine. 2004;7(4):551-7.

393 52. Bartlett MY, Condon P, Cruz J, Baumann J, Desteno D. Gratitude: Prompting behaviours 394 that build relationships. Cognition and Emotion. 2012;26(1):2-13.

395 53. Gordon AM, Impett EA, Kogan A, Oveis C, Keltner D. To have and to hold: Gratitude 396 promotes relationship maintenance in intimate bonds. Journal of Personality and Social 397 Psychology. 2012;103(2):257-74.

398 54. Gordon CL, Arnette RA, Smith RE. Have you thanked your spouse today?: Felt and 399 expressed gratitude among married couples. Personality and Individual Differences. $400 \quad 2011 ; 50(3): 339-43$. 
401 55. Lambert NM, Clark MS, Durtschi J, Fincham FD, Graham SM. Benefits of expressing 402 gratitude: Expressing gratitude to a partner changes one's view of the relationship. Psychological 403 Science. 2010;21(4):574-80.

404 56. Lambert NM, Fincham FD. Expressing gratitude to a partner leads to more relationship 405 maintenance behavior. Emotion. 2011;11(1):52-60.

406 57. Watkins PC, Woodward K, Stone T, Kolts RL. Gratitude and happiness: Development of 407 a measure of gratitude, and relationship with subjective well-being. Social Behavior and 408 Personality: an international journal. 2003;31(5):431-51.

409 58. Zerbe WJ, Paulhus DL. Socially Desirable Responding in Organizational Behavior: A 410 Reconception. The Academy of Management Review. 1987;12(2):250-64. 